\title{
POTENTIAL IMMUNOMODULATORY EFFECT OF SINGLE AND COMBINED THERAPIES AGAINST CRYPTOSPORIDIUM INFECTION IN IMMUNOSUPPRESSED MOUSE MODEL
}

\section{By}

\author{
MENNAT-ELRAHMAN A. FAHMY ${ }^{1}$, AMANY A. ABDELAAL ${ }^{283}$, SOAD I. HASSAN ${ }^{1}$, \\ MAISA A. SHALABY
1 , MOUSA A.M. ISMAIL
HANAA O. FADL ${ }^{2 *^{*}}$ \\ Department of Parasitology1, Theodor Bilharz Research Institute (TBRI), \\ Giza, Department of Medical Parasitology2, Faculty of Medicine, Cairo University, \\ Department of Medical Parasitology3, Armed Forces College of Medicine (AFCM), \\ and Department of Pathology4, Faculty of Medicine, Cairo University, Cairo, Egypt. \\ ( ${ }^{*}$ Correspondence: hoabdelmohsen@kasralainy.edu.eg)
}

\begin{abstract}
Cryptosporidium species are related to protozoan parasites that infect the gastrointestinal tract of a wide variety of animals, including humans. The host immune status is crucial for determining the susceptibility to infection, the outcome and the severity of the disease. Nitazoxanide ${ }^{\circledR}$ is the only FDA approved drug to treat such opportunistic infection, yet demonstrates limited and immune-dependent efficacy. The present work studied the effect of combination therapy in treating cryptosporidiosis, plus exploring the possible modulating effect on the local adaptive immune response in experimental dexamethasone immunocompromized mice model. The results showed that combination of selenium supplementation with ivermectin ${ }^{\circledR}$ or nitazoxanide improved the oocysts reduction percentage compared to groups receiving single anti-parasitic therapeutic drugs alone. Also, combination of ivermectin with nitazoxanide gave the best oocysts reduction rates with the lowest score of ileitis severity. But, local expression of CD4 T cells was down-regulated and unlikely could not be elevated enough even after all treatment types. CD8 was up regulated in all treated groups as compared with non-treated control group, indicating its possible role in reducing the serious threats of such opportunistic infection.
\end{abstract}

Keywords: Cryptosporidium- single therapy- combined therapies- CD4- CD8

\section{Introduction}

Cryptosporidium is an apicomplexan protozoon, which was reported as a human pathogen in 1976 by Nime. It is a leading cause of diarrheal death in children younger than five years, only second to rotaviral enteritis causing water- and food-borne diarrhea outbreaks in humans worldwide (Efstratiou et al, 2017; Ryan et al, 2018; Khalil et al, 2018). Considerable morbidity and mortality are frequently reported, specifically in immunodeficient individuals as a result of disease complications (Laurent and Lamande, 2017). Best possible therapy for cryptosporidiosis includes attention to fluids and electrolytes, antimotility agents, anti-parasitic drugs, nutritional support, and/or reversal of immunosuppression if achievable (Checkley et al, 2015; Wang et al, 2020). Effective drug treatment, particularly for infections in immunodeficient patients, has not been uni- formly successful. The current standard of care to treat Cryptosporidium infections, nitazoxanide, demonstrates limited and immune-dependent efficacy (Sparks et al, 2015; Widmer et al, 2020). Thus, drug combinations were tried to give a better response against cryptosporidiosis than using nitazoxanide alone (Theodos et al, 1998; Krause et al, 2012; Bhadauria et al, 2015).

Ivermectin is a semi-synthetic derivative of a family of macrocyclic lactones, with a broad-spectrum anti-parasitic, antiviral, and even as a cancer chemotherapeutic (Laing et al, 2017; Momekov and Momekova, 2020). In contrast, Selenium (Se) is an essential micronutrient known to influence the functioning of all components of the immune system, and its deficiency correlated with susceptibility or resistance to Cryptosporidium infection (Wang et al, 2009). So, with the increasing numbers of immune-altered patie- 
nts from various origins, cryptosporidiosis becomes an increasingly common problem which needs a treatment, not only as an antiparasitic agent but also, to improve the immune status of the patients.

The present work aimed to assess the effect of nitazoxanide and ivermectin drugs alone or combined together or combined with selenium on eliminating Cryptosporidium infection in immunocompromized experimentally infected mice. Also, to investigate the immunomodulatory impact of these therapeutic agents on the local expression of ileal CD4 \& CD8 T cell response.

\section{Materials and Methods}

Experimental animals: The study was carried out on 8 groups of laboratory-bred male Swiss albino mice of CD1 strain (6 mice/ each group); specific free pathogen (SFP), aged 7 weeks, and weighing 20-25gm each. Experimental mice were provided by Schistosoma Biological Supply Program (SBSP) at Theodor Bilharz Research Institute (TBRI). All experimental procedures were conducted in the Biological Unit of TBR, considering the internationally valid guidelines for animal experimentation. Each mouse was housed individually in a well-ventilated cage with clean wood-chip bedding, and provided with an ad libitum pelleted food and water under $18-23^{\circ} \mathrm{C}$ room temperature. Animals' stools were examined using direct wet saline smear and iodine, and then stained with acid fast stain to exclude any parasitic infection.

Experimental design: Mice were divided into 8 groups, 6 mice each as follows: I-Infected \& treated with single therapeutic agent: G1: treated with nitazoxanide (NTZ), \& G2: treated with ivermectin (IVC). II-Groups infected \& treated with combined therapies: G3: treated with nitazoxanide combined with ivermectin, G4: treated with nitazoxanide combined with selenium (Se), \& G5: treated with ivermectin combined with selenium. III- Control groups: Control 1 (C1): Normal non-infected non-treated (normal), Control 2 (C2): Non-infected (dexamethasone), \& (C3): Infected non- treated mice.
Induction of immune suppression by dexamethasone: Dexamethasone induced immune suppression was performed by giving all mice groups (except control normal group, C1) synthetic corticosteroids, dexamethasone (Dexazone: Al Kahira Pharmaceutical and Chemical Industries Company, Cairo), orally at a dose of $0.25 \mu \mathrm{g} / \mathrm{g} / \mathrm{day}$ for 14 successive days before inoculation with Cryptosporidium oocysts (Rehg et al, 1988). Mice were continued to receive dexamethasone at the same dose throughout the experiment.

Amplification of cryptosporidium oocysts and preparation of inoculum: Propagation of Cryptosporidium oocysts (obtained from faeces of infected calves) was achieved by in vivo amplification in 20 Swiss albino CD1 strain mice. Animals were inoculated repeatedly every 2 weeks by gavage as 2000 oocysts/animal (Oettingen et al, 2008). The oocysts were isolated and purified using centrifugal flotation (Zeibig, 1997). Purified oocysts were then suspended in PBS and kept with $0.01 \%$ Tween-20, containing $200 \mathrm{IU} /$ $\mathrm{mL}$ penicillin, $0.2 \mathrm{mg} / \mathrm{mL}$ streptomycin and $2.5 \mu \mathrm{g} / \mathrm{mL}$ amphotericin B eliminating any remaining bacterial or fungal contamination, and stored at $4{ }^{\circ} \mathrm{C}$ before use. In order to adjust the infecting dose of the oocyst in the inoculum, the number of Cryptosporidium oocysts in the suspension was determined by counting oocysts in smears prepared from $50 \mu \mathrm{l}$ aliquots and stained with Kinyoun's Acid Fast stain (Operario et al, 2015).

Infection: All mice groups (except normal non-infected control, C1) were orally infected with Cryptosporidium oocysts using oralgastric gavage. Each mouse was infected with Cryptosporidium oocysts in a dose of about $10^{4}$ oocysts/ mouse (Love et al, 2017).

Drug administration: 1- Nitazoxanide (Nanazoxid; Medizen Pharmaceutical Industries for Utopia Pharmaceuticals) was given orally in a suspension form in a dose of $250 \mathrm{mg} / \mathrm{kg} /$ body weight/day for 10 consecutive days (Theodos $e t$ $a l, 1998)$, and in a dose of $125 \mathrm{mg} / \mathrm{kg} / \mathrm{day}$ for 10 consecutive days as a part of combined therapy. 2- Ivermectin (Iverzine; Unipharma Alobour Ci- 
ty, Cairo) was given orally in a tablet form dissolved in distilled water in a dose of $2 \mathrm{mg} / \mathrm{kg}$ as a single oral dose (Zhang et al, 2008), and in a dose of $1 \mathrm{mg} / \mathrm{kg}$ single dose in combined therapy. 3- Selenium (Selenium-ACE; Sigma Pharmaceutical Industries for Interpharma, UK) was given orally $\mathrm{a}$ in a tablet form dissolved in distilled water in a dose of $2.5 \mu \mathrm{g} / \mathrm{ml}$ to for 14 consecutive days (Desowitz et al, 1980).

Mice scarification: Mice were sacrificed at the experimental end, 33 days post infection (PI) by receiving intraperitoneal anestheticanticoagulant solution $(500 \mathrm{mg} / \mathrm{kg}$ thiopental \& 100 units/ml heparin) (Liang et al, 1987). Terminal ileum was removed from each mouse, stored in $10 \%$ formalin for histopathological and immunohistochemical studies. After fixation, the tissues were dehydrated, cleared in ascending grades of ethanol, followed by immersion in xylene and then impregnated in paraffin blocks. Three sections of $5 \mu \mathrm{m}$ thickness were prepared from each paraffin block of each mouse; one was stained with H\&E stains, and other 2 sections were subjected to immunohistochemistry. Infection \& drug action were evaluated parasitological, histological and immunochemicaly.

Parasitological examination: For monitoring oocyst shedding, fresh fecal pellets from each infected mouse were collected from the $3^{\text {rd }}$ day PI $\&$ every 3 days until the experimental end. One gram of each fresh fecal sample was concentrated using formol/ether centrifugal sedimentation method (Arrowood, 1989), $50 \mu \mathrm{l}$ fecal smears was stained by Kinyoun's Acid-Fast stain (Garcia, 2001) and examined microscopically to count oocysts. For each animal, oocysts/gm feces were calculated (Benamrouz et al, 2012).

Histopathological examination: Intestinal (ileal) sections of mice were examined microsco-pically and the histopathological changes were recorded as mild, moderate, or marked, according to degree of inflammatory infiltrate in lamina propria, and villous mucosal architecture changes (villous height, brush border, and goblet cell content).

Immunohistochemical studies: For counti- ng CD4+ \& CD8+T lymphocytes, immunostaining of 2 intestinal sections (ileum) from each mouse was performed. Immunohistochemical staining was performed in an autostainer using a polymer-based detection system (DakoEnVision ${ }^{\mathrm{TM}}$ FLEX, K8000).

Tissue sections $(5 \mu \mathrm{m})$ of formalin-fixed \& paraffin-embedded specimens, were deparaffinized in xylene, rehydrated in descending grades of alcohol, and then incubated in hydrogen peroxide $3 \%$ for $5 \mathrm{~min}$. to block endogenous peroxidase activity. This was followed by washing twice in PBS (5min. each time). For antigen retrieval, tissue sections were placed in $0.01 \mathrm{~mol} / 1$ citrate buffer $(\mathrm{pH}$ 6) in an automated water bath (Dako PT link). This was followed by sections incubation with the primary antibody murine antihuman CD4 \& CD8 monoclonal antibodies (Dako, USA) at room temperature for $1 \mathrm{hr}$, and washed 3 times in PBS for $15 \mathrm{~min}$. each. Biotinylated goat anti-polyvalent secondary antibody and streptavidin Peroxidase enzyme were added consecutively for $10 \mathrm{~min}$ and washed in PBS. Peroxidase activity was visualized with diaminobenzidine (DAB) chromogen applied for 5 min (Ramos-Vara and Miller, 2014). Tissue sections were rinsed, counterstained with hematoxylin, dehydrated, cleared in xylene, and mounted in DPX. Sections from tonsils were used as positive control according to the manufacturer's reco mmendation. Negative control was processed, except for the primary antibody usage. T lymphocytes expressing membranous or cytoplasmic brownish immunostaining for CD4 or CD8 were considered positive. Counting of CD4+ and CD8+ T lymphocytes in intestinal villi lamina propria were performed in 5 representative high-power fields $(\times 400)$, and the average of cells/ HPF for each sacrificed mouse of groups (Casol et al, 2013).

Statistical analysis: Data was coded and entered using the statistical package SPSS version 25 . Numerical data was summarized using mean, standard deviation and range. Comparisons between groups were done using analysis of variance (ANOVA) with mul- 
tiple comparisons post hoc test. Chi-square test $\left(\chi^{2}\right)$ was used to study comparison and association between two qualitative variables. Independent t-test used between every two groups having quantitative variables. A $\mathrm{P}$-value of $<0.05$ was considered significant and $<0.001$ for a high significant result.

\section{Results}

Comparison to control group (C3, infected, non-treated), gave the best reduction rate (81\%) among mice infected \& treated with combined nitzoxanide and ivermectin that gave the least oocysts count compared to group C3 (Fig. 1). Least reduction (39\%) was in mice treated with nitazoxanide, followed by $(59 \%)$ mean reduction in treated with combined nitazoxanide and selenium. Reduction rate in mice only treated with ivermectin $(63 \%)$ and $(70 \%)$ in mice treated with ivermectin and selenium. There was significant difference $(p<0.001)$ between C3 and all dexamethasone infected and treated groups, as regard Cryptosporidium oocysts concentration in one gram feces (Tab. 1).

Among dexamethasone treated, infected and treated groups, there was a significant difference in mean number of excreted Cryptosporidium oocysts between $\mathrm{G} 1$ and other dexamethasone treated, infected and treated $(\mathrm{p}<0.001)$. G2, G4 \& G5 or between G3 \& G5 oocysts shedding were without significant $(\mathrm{P}>0.05)$. The ileitis severity was maximized by the parasite in $\mathrm{C} 3$, infected non-treated, in which $83.3 \%$ of infected animals showed severe inflammatory response and marked villous changes including remarkable shortening and blunting of some villi, atrophy of other villi, sloughing of the brush border and depletion of goblet cell content. Only $16.7 \%$ showed moderate inflammatory and villous architectural changes. Significantly slighter inflammatory response and mild villous changes were noticed in all dexamethasone treated, infected and treated groups compared to control (C3) $(\mathrm{P}<0.001)$ (Tab. 2, Fig. 2). The best severity improvement after treatment was in mice received combined therapy (G3, NTZ + IVC), where only $16.7 \%$ showed moderate inflammatory and mild villous changes, but the other mice group $(83.3 \%)$ showed mild inflammation and mild villous changes (Fig. 3 ), with significant difference in severity of ileitis between this group and all other treated group $(\mathrm{P}<0.001)$, except G5 (IVC \& Se). There was no significant difference between G2 \& G4 or G5) as to ileitis severity (P > $0.05)$.

Regarding the number of local ileal CD4 T-lymphocytes, there was a significant reduction in all groups compared to $\mathrm{C} 1$ and other groups $(\mathrm{P}<0.001)$, with the least count in dexa $\mathrm{C} 2$. There was significant elevation of $\mathrm{T}$ cell population in all treated groups $(\mathrm{P}<0.001)$ compared to control infected nontreated mice. Treated groups showed significant elevation compared to $\mathrm{C} 2 \quad(\mathrm{P}<0.001)$ except mice treated with NTZ $(\mathrm{P}>0.05)$. As regards the number of local ileal CD8 Tlymphocytes, there was a significant reduction in infected non-treated group, compared to control normal group $(\mathrm{P}<0.001)$. There was a significant elevation of CD8 $\mathrm{T}$ cell population in all treated groups $(\mathrm{P}<0.001)$ compared to control infected non-treated. Besides, treated groups showed significant elevation compared to $\mathrm{C} 2$, dexa only, noninfected $(\mathrm{P}<0.001)$ (Tab. 3 Fig.2).

Table 1: Mean number of Cryptosporidium oocysts in one gram of feces at experimental end.
\begin{tabular}{|l|c|c|c|c|}
\hline \multirow{2}{*}{ Groups } & \multicolumn{2}{|c|}{ Range } & M \pm SD & $\begin{array}{c}\text { Reduction } \\
\%\end{array}$ \\
\cline { 2 - 3 } & Minimum & Maximum & & \\
\hline Infected, non-treated (C3) & 99000 & 170000 & $130166 \pm 28371.93^{\mathrm{a}}$ & $39 \%$ \\
\hline Infected + NTZ (G1) & 59500 & 105000 & $80000 \pm 19750.95^{\mathrm{b}}$ & $63 \%$ \\
\hline Infected + IVC (G2) & 33000 & 71000 & $48500 \pm 15056.56^{\mathrm{c}}$ & $81 \%$ \\
\hline Infected + NTZ +IVC (G3) & 16000 & 35000 & $25000 \pm 7429.67^{\mathrm{d}}$ & $59 \%$ \\
\hline Infected + NTZ+Se (G4) & 40000 & 69000 & $53000 \pm 11081.52^{\mathrm{c}}$ & $59 \%$ \\
\hline Infected + IVC +Se (G5) & 29000 & 55000 & $39000 \pm 9444.58^{\mathrm{c}, \mathrm{d}}$ & $70 \%$ \\
\hline
\end{tabular}

a, b, c \& d: No significant difference $(\mathrm{P}>0.05)$ between any two groups, within same column with same superscript letter. 
Table 2: A comparison of histopathological changes included degree of inflammatory infiltrate and villous architectural changes between different groups.

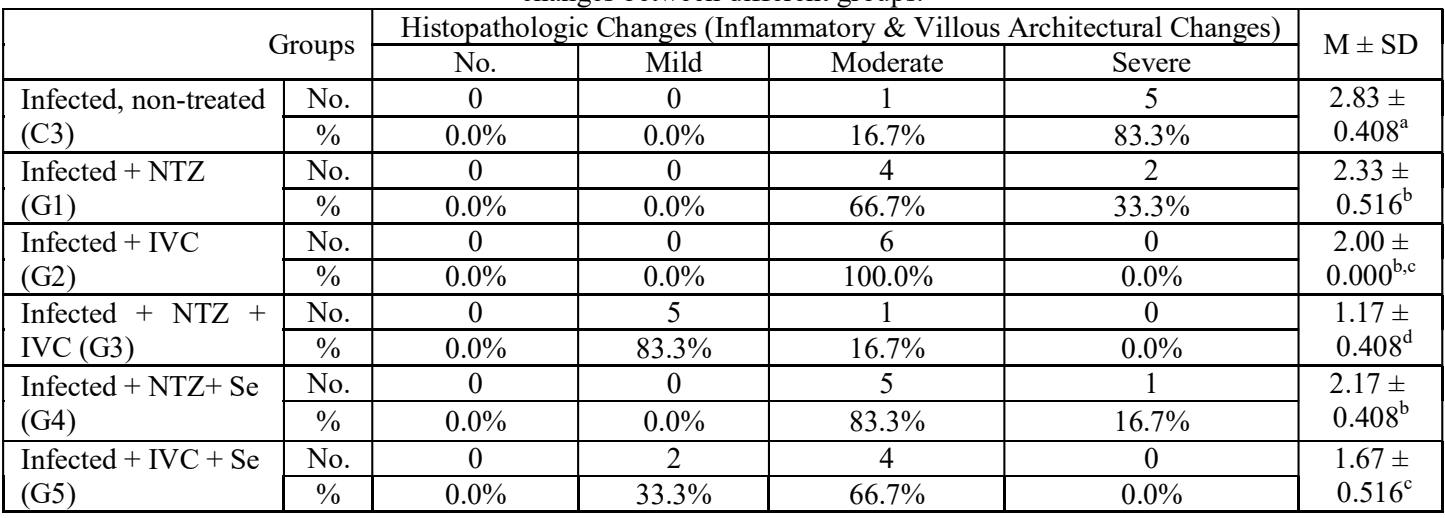

a, b, c \& d: No significant difference ( $\mathrm{P}>0.05)$ between any two groups, within same column with same superscript letter.

Table 3: A comparison between groups, regarding CD4 \&CD8 count in lamina propria of intestinal villi.

\begin{tabular}{|l|l|l|}
\hline Groups & $(\mathrm{CD} 4)$ & $(\mathrm{CD} 8)$ \\
\hline Normal (C1) & $16.8 \pm 1.49^{\mathrm{a}}$ & $10.2 \pm 0.87^{\mathrm{e}}$ \\
\hline Dexa only (C2) & $5.00 \pm 0.75^{\mathrm{d}}$ & $6.3 \pm 0.8832^{\mathrm{f}}$ \\
\hline Infected, non-treated (C3) & $4.00 \pm 0.58^{\mathrm{e}}$ & $6.0 \pm 0.8319^{\mathrm{f}}$ \\
\hline Infected + NTZ (G1) & $5.2 \pm 0.62^{\mathrm{d}}$ & $12.0 \pm 1.15^{\mathrm{d}}$ \\
\hline Infected + IVC (G2) & $6.8 \pm 0.64^{\mathrm{c}}$ & $14.4 \pm 1.02^{\mathrm{c}}$ \\
\hline Infected + NTZ + IVC (G3) & $6.6 \pm 0.50^{\mathrm{c}}$ & $15.0 \pm 1.65^{\mathrm{c}}$ \\
\hline Infected + NTZ+ Se (G4) & $7.6 \pm 0.70^{\mathrm{b}, \mathrm{c}}$ & $17.4 \pm 1.63^{\mathrm{b}}$ \\
\hline Infected + IVC + Se (G5) & $8.0 \pm 0.79^{\mathrm{b}}$ & $20.0 \pm 2.07^{\mathrm{a}}$ \\
\hline
\end{tabular}

a, b, c \& d: No significant difference $(\mathrm{P}>0.05)$ between any two groups, within same column with same superscript letter.

\section{Discussion}

The immune status of the host generally plays an important role in determining susceptibility to cryptosporidiosis outcome and seriousness of the disease (Borad and Ward, 2010). Nitazoxanide was approved by the FDA to treat cryptosporidiosis. However, the efficacy of nitazoxanide depends upon a capable immune system. Thus, it demonstrates very poor efficacy in AIDS and other immunocompromized categories of patients which highlight an urgent medical need for such type of patients (Sparks et al, 2015; Love et al, 2017). Improvement in cellular immune function among these categories was a key priority for management of cryptosporidiosis (Checkley et al, 2015; Ahmadpour et al, 2020). Thus, resolution of this opportunistic infection was seen following CD4+ $T$ cell reconstitution in immunocompromized patients given antiretroviral therapy, indicating importance of such set of cell population in serious infection (O'Connor $e t$ $a l$, 2011; Ludington and ward, 2015). Combination drug therapy is recommended as alternative promising strategy against cryp- tosporidiosis. It is defined as the use of two or more pharmacologic agents administered separately or in a fixed-dose amalgamation with two or more active ingredients in a single-dosage formulation (Terrie, 2010). Thus, the latter was assessed in this study, in comparison to the commonly used single FDA approved therapeutic agent.

Ivermectin was chosen in the present study to combine nitazoxanide in one group and selenium was the other choice to be given in combination with each anti-parasitic agent, exclusively in separate groups. Ivermectin is a semi-synthetic derivative of macrocyclic lactones family with broad-spectrum antiparasitic, antiviral, and anti-cancer chemotherapeutic (Chhaiya et al, 2012; Laing et al, 2017; Momekova, 2020). It is active against acute and chronic giardiasis, cryposporidiosis. and for mass treatment for malaria due to its ability to kill mosquitoes feeding on recently treated patients (Shalaby and Hagg ag, 2006; Smit et al, 2018). Selenium (Se) is an essential micronutrient with pivotal role in maintaining optimal health through its incorporation into selenoproteins (Gill 
and Walker, 2008). Selenium is known to influence the functioning of all components of the immune system, and its deficiency has been reported to reduce the production of free radicals and killing capacity of neutrophils, $\mathrm{T}$ cell counts, proliferation and differentiation of $\mathrm{T}$ cells, lymphocyte toxicity and NK cell activity (Arthur et al, 2003; Ferencik et al, 2003; Gill and Walker, 2008). Wang et al. (2009) found that susceptibility or resistance to infection with Cryptosporidium parvum correlates with Selenium (Se) deficiency in response to infection.

In the current work, the highest percentage of oocysts reduction was recorded among the group that received combination therapy (IVC \& NTZ, 81\%), and the lowest oocysts reduction was among nitazoxanide only (39\%), indicating its inefficiency to eradicate such intestinal opportunistic protozoal infection. While, therapy combined with Se supplementation improved the percentage of oocysts reduction with both IVC \& NTZ to reach $70 \%$ \& $59 \%$ with the single agent respectively, indicating the superiority of both IVC and combined therapy over NTZ alone. Blakley and Rousseaux (1991) found immunostimulatory properties for ivermectin associated with altered function of $\mathrm{T}$ lymphocytes, particularly T-helper lymphocytes. Ivermectin has influence on cellular and humoral immune responses, and immunopotentiating effect in rabbits (Sajid et al, 2007; Zhang et al, 2008; Omer et al, 2012). So, its immunomodulating effects gave an alternative treatment for diseases involving immunosuppression.

The histopathological changes of ileocecal sections observed in the current study within the infected non treated groups showed remarkable effect on the structure of the intestinal mucosa (mild, moderate \& severe ileitis) compared with that of the non-infected control group. This effect was in the form of shortening or atrophy of the villi, goblet cell depletion, edema and infiltration of lamina propria with mononuclear inflammatory ce1ls that agreed with Waters and Harp (1996) who found variable histopathologic changes in cryptosporidiosis ranged from partial to complete villous atrophy and inflammatory infiltrate. Similar histopathological findings were also reported (Al-Mathal and Alsalem, 2012; Al-Warid et al, 2013). There was a significant difference in severity of ileitis between infected treated and non-treated groups with the lowest score of ileitis severity in the treated group with combined treatment $(83.3 \%$ mild \& $16.7 \%$ moderate ileal inflammatory and villous changes), comp0ared to infected non treated group (16.7\% moderate and $83.3 \%$ severe ileal inflammatory changes). Therapy combined with supplementation in dexamethasone treated, infected and treated groups improved the severity of ileitis non-significantly $(\mathrm{P}>0.05)$ in both groups treated with (NTZ \& Se) and treated with (IVC \& Se).

In the present study, $\mathrm{T}$ cells included the $\mathrm{CD}^{+} \mathrm{T}$ cells and $\mathrm{CD} 8^{+} \mathrm{T}$ cells and the ratio between these 2 immune elements were recognized as an important indicator for evaluating the immunomodulation state and response to homeostasis of intrinsic immune system (Wang et al, 2016). In all dexamethasone treated groups, CD4 were more affected but could not be elevated enough even after treatment. Thus, reflected the importance of early diagnosis and treatment to prevent unnecessary complications. CD8 significantly increased in all treated groups with a reversed and unbalanced ratio of CD4/CD8 within the intestinal lesions, compared to normal ones. This agreed with Rocamora-Reverte et al. (2019) who found that CD4+ Tcells were essential target cells affected by glucocorticoids (GC), and most affected by immune suppression. This explained the lower level within the local CD4, but did not explain the high level in CD8 in all infected and treated groups. Korbel et al. (2011) reported that the proportion of intestinal $\mathrm{CD} 4^{+}$or $\mathrm{CD} 8^{+} \mathrm{T}$ cells did not increase infection in infected mice during recovery. This suggested that even if $\mathrm{CD}^{+} \mathrm{T}$ cells were important to eliminate $C$. parvum, but were possibly unnecessary for 
controlling infection in mice. On the contrary, many authors suggested a greater role for CD8 in elimination of such infection and this may explain such elevation in the treated group to cope with the hard immunological task needed by the host to eradicate the infection helped by effective forms of the treatment (Rowe et al, 2007).

The present study, higher elevation in CD8 count over CD4 in all treated groups, compared to both normal and infected non treated groups were more or less agreed with Miller and Schaefer (2007) who studied the impact of dexamethasone induced immunosuppression on mice infected with Cryptosporidium oocysts. The authors reported that, the CD8 counts in such group were only $1.6 \%$ below controls, while CD4 counts was still depressed by $66 \%$, reflected by GC much higher power to depress CD4 than CD8. They added that these corresponded to cryptosporidiosis elimination and that CD8 positive lymphocytes played a significant role parasite clearance in vivo. Pantenburg et al. (2010) found that CD8 (+) T cells eradicated intestinal epithelial zoonotic cryptosporidiosis. So, the CD8 high level was ineffective in dexamethasone treated groups to eradicate total infection.

Tessema et al. (2007) found that transfer of CD4+ and CD8+ T-cells (pan T-cells) did not provide a better protection of naive recipients than CD4+ T-cells alone, with irrelevance of CD8+ T-cells in protection against cryptosporidiosis. Possible scenarios from other intracellular pathogens rose existence of Cryptosporidium immune evasion mechanism by CD8+ T-cell-mediated cytotoxicity. Lysosomal degradation of $C$. parvum intracellular developmental stages was required to recognize Cryptosporidium infected host cells by CD8+ T-cells. Autophagy of intracellular pathogens contributed to effective elimination of viruses, bacteria \& parasites, but, many pathogens escaped autophagy machinery as herpes simplex virus type 1 and Shigella use proteins to antagonize autophagy (Orvedahl et al, 2007). Ability of patho- gens to escape autophagy allowed survival within host cells as a new immune mechanism evasion (Vyas et al, 2008), and Cryptosporidium location within cells was worth mentioned (Crotzer and Blum, 2008).

All stages of Cryptosporidium were located in a parasitophorous vacuole, formed extra-cytoplasmic, but intracellular within infected cells. The structure could hinder lysosomal degradation of Cryptosporidium proteins to be presented through MHC-I pathway. Lack of MHC-I C. parvum proteins was the cause why CD8+ T-cells do not kill infected cells. After degradation of antigens from intracellular pathogens, peptides from degraded antigen bind to MHC-I molecule on the infected cell surface for recognition by CD8+ T cells. Aguirre et al. (1994) found that MHC-II (important for CD4+ T-cells) deficient mice were more susceptible to $C$. parvum infection than MHC-I deficient mice (important for function of CD8+ T-cells). $C$. parvum modulated the MHC-I Ag presentation pathway without pathogenic antigen on epithelial infected cells surface to be recognized by CD8+T-cells (Hewitt, 2003).

\section{Conclusion}

The outcome results proved the superior effectiveness of the combined treatment over the other forms of treatment and the inferiority of NTZ alone. Studies to assess other drug combination with variable doses for more effective Cryptosporidium eradication specifically in immunocompromized models are ongoing and will be published later.

\section{References}

Al-Mathal, EA, Alsalem, MA, 2012: Pomegranate (Punica granatum) peel is effective in a murine model of experimental Cryptosporidium parvum. Exp. Parasitology 131:350-7.

Aguirre, SA, Mason, PH, Perryman, LE, 1994: Susceptibility of major histocompatibility (MHC) class I- and class II-deficient mice to Cryptosporidium parvum infection. Infection and Immunity 62: 697-9.

Al-Warid, HS, AL-Saqur, IM, Mahmood, SH, 2013: Histopathological changes in mice infected with Cryptosporidium spp. Int. J. Pharm. Bio. Sci. 3, 3:220-7. 
Arrowood, MJ, Sterling, C, 1989: Comparison review of worldwide outbreaks: An update 2011-2016. Water Res. 114:14-22

Arthur, JR, Nicol, F, Hutchinson, AR, Beckett, GJ, 1990: The effects of selenium depletion and repletion on the metabolism of thyroid hormones in the rat. J. Inorg. Biochem. 39, 2101-8.

Benamrouz, S, Guyot, K, Gazzola, S, Mouray, A, Chassat, T, et al, 2012: Cryptosporidium parvum infection in SCID mice infected with only one oocyst: qPCR assessment of parasite replication in tissues and development of digestive cancer. PLoS One 7, 12:512-32.

Bhadauria, D, Goel, A, Kaul, A, Sharma, RK, Gupta, A, et al, 2015: Cryptosporidium infection after renal transplantation in an endemic area. Transpl. Infect. Dis. 17, 1:48-55.

Blakley, BR, Rousseaux, CG, 1991: Effect of ivermectin on the immune response in mice. Am. J. Vet. Res. 52, 4:593-5.

Borad, A, Ward, H, 2010: Human immune responses in cryptosporidiosis. Fut. Microbiol. 5: 507-19.

Cassol, E, Malfeld, S, Mahasha, P, Bond, R, Slavik, T, et al, 2013: Impaired CD4+ T-Cell resto-ration in the small versus large Intestine of HIV-1-Positive South Africans receiving combination anti-retroviral therapy. J. Infect. Dis. 208, 7:1113-22.

Checkley, White, AC Jr, Jaganath, D, Arrowood, MJ, Chalmers, R.M.; Chen, X.M et al, 2015: A review of the global burden, novel diagnostics, therapeutics, and vaccine targets for Cryptosporidium. Lancet Infect. Dis. 15:85-94.

Chhaiya, SB, Patel, VJ, Dave, JN, Mehta, D S, Shah, HA, 2012: Comparative efficacy and safety of topical permethrin, topical ivermectin, and oral ivermectin in patients of uncomplicated scabies. Indi. J. Dermatol. Venereol. Leprol.78, 5: 605-10.

Crotzer, VL, Blum, JS, 2009: Autophagy and its role in MHC-mediated antigen presentation. J. Immunol. 182, 6:3335-41.

Desowitz, RS, Barnwell, JW, 1980: Effect of selenium and dimethyl dioctadecyl ammonium bromide on the vaccine-induced immunity of Swiss-Webster mice against malaria (Plasmodium berghei). Infect. Immun. 27, 1:87-9.

Efstratiou, A, Ongerth, JE, Karanis, P, 2017: Waterborne transmission of protozoan parasites: of conventional staining methods and monoclonal antibody-based methods for Cryptosporidi- um oocyst detection. J. Clin. Microbiol. 27: 1490-5.

Ferencik, M, Ebringer, L, 2003: Modulatory effects of Selenium and Zinc on the immune system. Folia Microbiol. 48, 3:417-26.

Garcia, LS, 2001: Diagnostic Medical Parasitology. $4^{\text {th }}$ Ed. ASM Press, Washington, DC.

Gill, H, Walker, G, 2008: Selenium, immune function and resistance to viral infections. Nutrition \& Dietetics 65, 3:41-7.

Hewitt, EW, 2003: The MHC class I antigen presentation pathway: Strategies for viral immune evasion. Immunol. 110, 2:163-9.

Khalil, IA, Troeger, C, Rao, PC, Blacker, BF, Brown, A, et al, 2018: Morbidity, mortality, and long-term consequences associated with diarrhea from Cryptosporidium infection in children younger than 5 years: A meta-analyses study. Lancet Glob. Hlth. 6:758-68.

Korbel, DS, Barakat, FM, Di Santo, JP, McDonald, V, 2011: CD4+ T cells are not essential for control of early acute Cryptosporidium parvum infection in neonatal mice. Infect. Immun. 79, 4:1647-53.

Krause, I, Amir, J, Cleper, R, Dagan, A, 2012: Cryptosporidiosis in children following solid organ transplantation. Pediatr. Infect. Dis. J. 311, 1:1135-8.

Laing, R, Gillan, V, Devaney, E, 2017: Ivermectin: Old Drug, New Tricks? Tren. Parasitol. 33, 6: 463-72.

Laurent, F, Lacroix-Lamandé, S, 2017: Innate immune responses play a key role in controlling infection of the intestinal epithelium by Cryptosporidium. Int. J. Parasitol. 47, 12:711-21.

Liang, YS, Bruce, JI Boyd, DA, 1987: Proceeding of the First Sino-American Symposium 1: 34-48.

Love, MS, Beasley, FC, Jumani, RS, Wright, TM, Chatterjee, AK, et al, 2017: A high throughput phenotypic screen identifies clofazimine as a potential treatment for cryptosporidiosis. PLoS Negl. Trop. Dis. 11, 2:e0005373.

Ludington, JG, Ward, HD, 2015: Systemic and mucosal immune responses to Cryptosporidium: Vaccine development. Curr. Trop. Med. Rep. 2, 3:171-80.

Miller, TA, Schaefer, FW, 2007: Changes in mouse circulating leukocyte numbers in C57BL/ 6 mice immunosuppressed with dexamethasone for Cryptosporidium parvum oocyst production. Vet. Parasitol. 149, 3/4: 147-57. 
Momekov, G, Momekova, D, 2020: Ivermectin as a potential COVID-19 treatment from the pharmacokinetic point of view: antiviral levels are not likely attainable with known dosing regimens. Biotechnol. Biotechnol. Equip. 34, 1:469-74.

Nime, FA, Burek, JD, Page, DL, Holscher, M A, Yardley, JH, 1976: Acute enterocolitis in a human being infected with the protozoan Cryptosporidium. Gastroenterology 70:592-8.

O'Connor, RM, Shaffie, R, Kang, G, Ward, H D, 2011: Cryptosporidiosis in patients with HIV/ AIDS. AIDS 25:549-60.

Oettingen, JV, Nath-Chowdhury, M, Ward, B J, Rodloff, AC, Arrowood, MJ, et al, 2008: High-yield amplification of Cryptosporidium parvum in interferon c receptor knockout mice. Parasitology 135:1151-6.

Omer, MO, Ashraf, M, Javeed, A, Maqbool, A, 2012: Immunostimulatory effect of ivermectin on macrophage engulfment and delayed type hypersensitivity in broilers. J. Anim. Plant Sci. 22, 2:250-5.

Operario，DJ, Bristol，LS, Liotta，J, Nydam, DV, Houpt, ER, 2015: Correlation between diarrhea severity and oocyst count via quantitative PCR or fluorescence microscopy in experimental cryptosporidiosis in calves. Am. J. Trop. Med. Hyg. 92, 1:45-9.

Orvedahl, A, Alexander, D, Talloczy, Z, Sun, Q, Wei, Y, et al, 2007: HSV-1 ICP34.5 confers neurovirulence by targeting the beclin 1 autophagy protein. Cell Host Microbe 1:23-35.

Pantenburg, B, Castellanos-Gonzalez, A, Dann, SM, Connelly, RL, Lewis, DE, et al, 2010: Hum-an CD8 (+) T cells clear Cryptosporidium parvum from infected intestinal epithelial cells. Am. J. Trop. Med. Hyg. 82:600-7.

Ramos-Vara, JA, Miller, MA, 2014: When tissue antigens and antibodies get along: Revisiting the technical aspects of immunohistochemistry: The red, brown, and blue technique. Vet. Pathol. 51, 1:42-87.

Rehg, JE, Hancock, ML, Woodmansee, DB, 1988: Characterization of a dexamethasone-treated rat model of cryptosporidial infection. J. Infect. Dis. 158:1406-7.

Rocamora-Reverte, L, Tuzlak, S, von Raffay, L, Tisch, M, Fiegl, H, et al, 2019: Glucocorticoid receptor-deficient Foxp $3^{+}$regulatory T cells fail to control experimental inflammatory bowel disease. Front Immunol. 10:472-6.

Rowe, M, Glaunsinger, B, Leeuwen, DV, Zuo, J, Sweetman, D, et al, 2007: Host shutoff dur- ing productive Epstein-Barr virus infection is mediated by BGLF5 and may contribute to immune evas- ion. PNAS 104, 9:3366-71.

Ryan, U, Hijjawi, N, Xiao, L, 2018: Foodborne cryptosporidiosis. Int. J. Parasitol. 48:1-12.

Sajid, MS, Iqbal, Z, Muhammad, G, Sandhu, MA, Khan, MN, et al, 2007: Effect of ivermectin on the cellular and humoral immune responses of rabbits. Life Sci. 80, 21:1966-70.

Shalaby, MA, Haggag, SH, 2006: Effect of the antiparasitic agent ivermectin on cryptosporidiosis in experimental animals. Egypt. J. Med. Sci. 27, 2:635-48.

Smit, MR, Ochomo, E, Aljayyoussi, G, Kwambai, T, OAbong'o, B et al, 2018: Safety and mosquitocidal efficacy of high-dose ivermectin when co-administered with dihydroartemisininpipera-quine in Kenyan adults with uncomplicated malaria (IVERMAL): A randomised, double-blind, placebo-controlled trial. Lancet Infect. Dis. 18, 6: 615-26.

Sparks, H, Nair, G, Castellanos-Gonzalez, A, White, JA 2015: Treatment of Cryptosporidium: What we know, gaps, and the way forward. Curr. Trop. Med. Rep. 2, 3:181-7.

Terrie, YC. 2010: Monitoring combination drug therapy. Pharm. Times 76, 1:10-8.

Tessema, TS, Schwamb, B, Lochner, M, Förster, I, Jakobi, V, et al, 2009: Dynamics of gut mucosal and systemic Th1/Th2 cytokine responses in interferon-gamma and interleukin-12p40 knockout mice during primary and challenge Cryptosporidium parvum infection. Immunobiology 214, 6:454-66.

Theodos, CM, Griffiths, JK, D'Onfro, J, Fairfield, A, Tzipori, S, 1998: The efficacy of nitazoxanide against $C$. parvum in cell culture and in animal models. Antimicrob. Agen. Chemother. 42, 8:1959-65.

Vyas, JM, Van der Veen, AG, Ploegh, HL, 2008: The known unknowns of antigen processing and presentation. Nat. Rev. Immunol. 8, 8: 607-18.

Widmer, G, Carmena, D, Kváč, M, Chalmers, RM, Kissinger, JC, et al, 2020: Update on Cryptosporidium spp.: Highlights from $7^{\text {th }}$ Inter. Giardia and Cryptosporidium Conf. Parasite 27:14. Wang, B, Alejandro Castellanos-Gonzalez, A, White, J, 2020: Novel drug targets for treatment of cryptosporidiosis. Expert Opin. Therap. Targ. 24, 9:915-22

Wang, C, Wu, Y, Qin, J, Sun, H, He, H, 2009: Induced susceptibility of host is associated with 
an impaired antioxidant system following infection with Cryptosporidium parvum in Sedeficient mice. PLoS One 4, 2:e4628.

Wang, Z, Wang, Y, Xu, B, Liu, J, Ren, Y, et al, 2016: Vitamin D improves function in immuno-suppressant mice induced by glucocorticoid. Biomed. Rept. 6, 1:120-4.

Waters, WR, Harp, JA, 1996: Cryptosporidium parvum infection in T-cell receptor (TCR)- alpha- and TCR-delta-deficient mice. Infect. Immun. 64:1854-7.

Zeibig, EA, 1997: Clinical Parasitology, W.B Saunders Company; Philadelphia

Zhang, X, Song, Y, Ci, X, An, N, Ju, Y, et al, 2008: Ivermectin inhibits LPS-induced production of inflammatory cytokines and improves LPS-induced survival in mice. Inflamm. Res. 57, 11:524-9.

\section{Explanation of figures}

Fig. 1: Column chart showed Cryptosporidium oocysts expelled/ gram feces in different treated groups.

Fig. 2: CD4 (left) \& CD8 (right) within control normal and control non-infected groups. Notice apparently higher expression of CD4 in normal group (A) and relatively lower expression of CD4 in dexa group (C) \& the higher expression of CD8 (D) than in control normal (B). CD4 \& CD8 appear still down regulated within dexa infected non-treated group (E\&F). On the contrary, expression of CD8 intensifies over CD4 within dexa infected treated group $(\mathrm{G} \& \mathrm{H})$.

Fig. 3: Sections of ileum from different degrees of ileitis. A: infected, non-treated group showed severe villous change. B: Treated, infected group treated with NTZ only showing moderate to severe ileitis. C: Treated, infected group treated with IVC or NTZ \& Se showed moderate ileitis. D: Mild villous changes in infected group treated with combined therapeutic agent with IVC (NTZ \& IVC or IVC \& Se) (Hx \& E stain x 200).

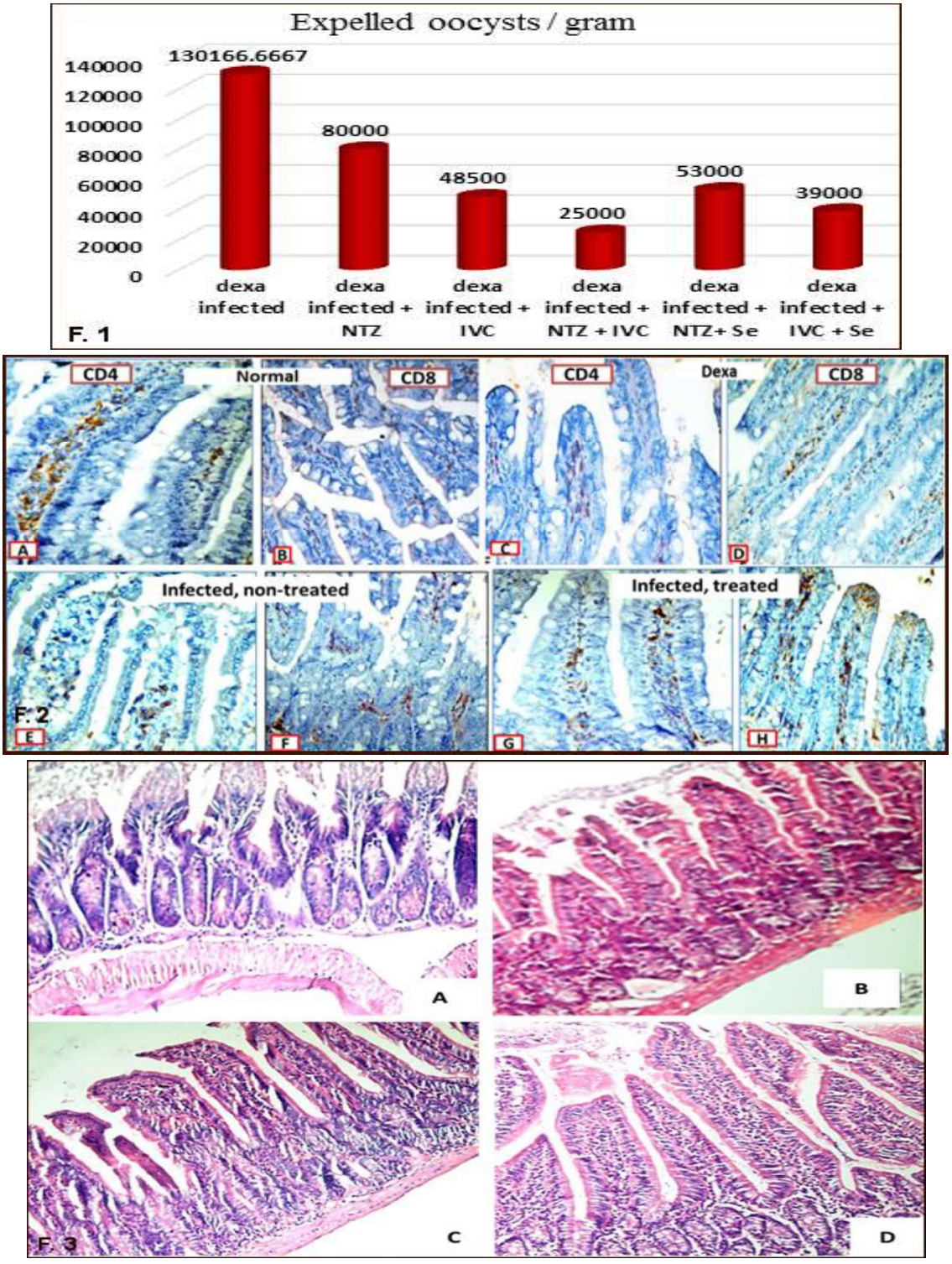

